\title{
Erratum: Topological excitations and the dynamic structure factor of spin liquids on the kagome lattice
}

Matthias Punk, Debanjan Chowdhury and Subir Sachdev

Nature Physics 10, 289-293 (2014); published online 9 March 2014; corrected after print 22 April 2016.

In the version of this Letter originally published square root symbols were mistakenly included in the $x$-axis tick labels in Figure $3 a-d$. This has now been corrected in the online versions of the Letter.

Figure 3

a

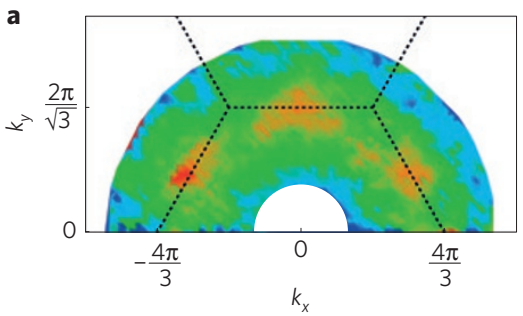

c

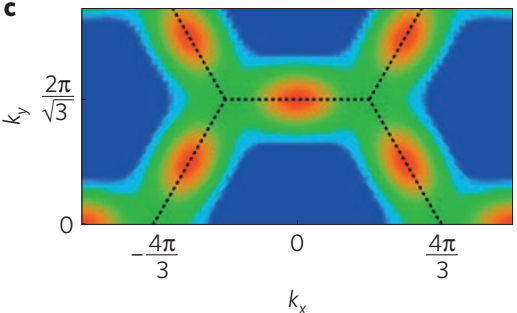

b

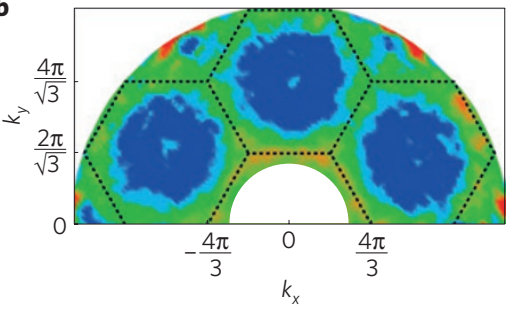

d

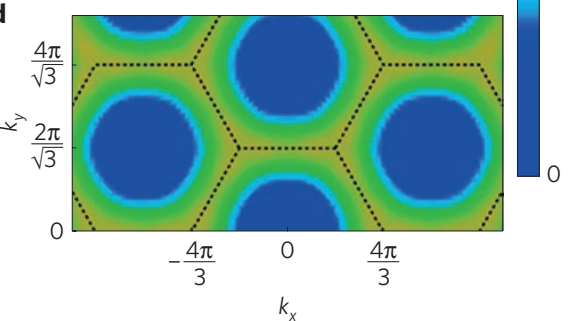

e
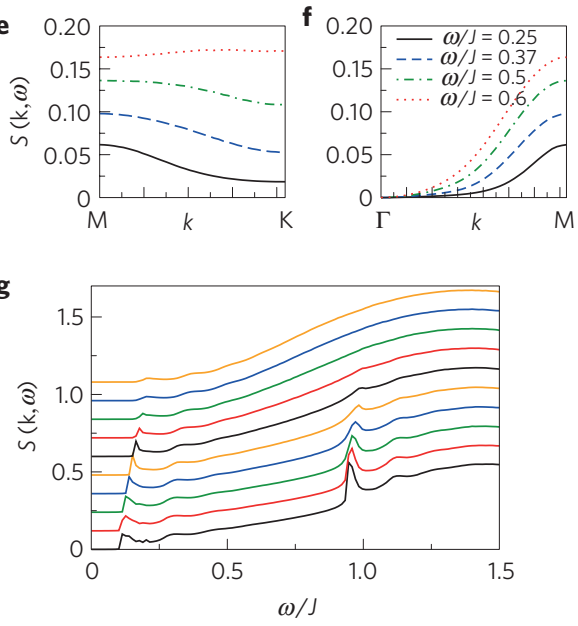